\title{
Differences in and verification of genetic alterations in chemotherapy and immunotherapy for metastatic melanoma
}

\author{
Yang $\mathrm{Li}^{1}$, Yuling Gao ${ }^{1}$, Weiling $\mathrm{Chu}^{1}$, Jianjian $\mathrm{Lv}^{2}$, Zhi $\mathrm{Li}^{1}$, Tongxin Shi ${ }^{1}$ \\ ${ }^{1}$ Department of Dermatology, The Affiliated Qingdao Municipal Hospital of Qingdao University, Qingdao, \\ Shandong, China \\ ${ }^{2}$ Department of Oncology, The Affiliated Qingdao Municipal Hospital of Qingdao University, Qingdao, Shandong, \\ China
}

Correspondence to: Tongxin Shi; email: 2009020212@st.btbu.edu.cn Keywords: metastatic melanoma, prognostic factor, chemotherapy, immunotherapy, resistance-related genes, genetic alterations Received: July 28, 2021 Accepted: September 29, 2021 Published: October 21, 2021

Copyright: (C) $2021 \mathrm{Li}$ et al. This is an open access article distributed under the terms of the Creative Commons Attribution License (CC BY 3.0), which permits unrestricted use, distribution, and reproduction in any medium, provided the original author and source are credited.

\section{ABSTRACT}

Background: Metastatic melanoma has poor therapeutic response and may present resistance to chemotherapy or immunotherapy. Significant differences are observed in the survival time of patients with metastatic melanoma based on the administration of chemotherapy or immunotherapy; thus, we have explored the important role of specific differential genes between the two therapies in their effect on treatment response in melanoma.

Methods: Metastatic melanoma gene expression data (RNAseq, mutation and methylation) and patient clinical information were downloaded from The Cancer Genome Atlas database and grouped according to chemotherapy or immunotherapy. The differentially expressed genes of the two groups were further screened for signature genes through a protein-protein interaction network and Lasso-Cox regression model. Then, differences in the treatment response, overall survival, mutation and methylation of characteristic genes were compared. Finally, western blot and real-time qPCR technology were used to detect the expression differences of the signature genes in metastatic melanoma tumor tissues in patients undergoing chemotherapy and immunotherapy.

Results: The overall survival of the chemotherapy-based treatment group was significantly higher than that of the immunotherapy-based group. The immune infiltration level of immature dendritic cells (DCs) in the chemotherapy group was significantly higher than that in the immunotherapy group. Finally, seven signature genes were selected: CCKBR, KCNJ11, NMU, MMP13, ITGA10, IGFBP1 and CEACAM5. The results of these signature genes were significantly differentiated between the chemotherapy and immunotherapy groups in terms of overall survival and disease progression in response to treatment. In addition, differences in the expression of these genes were verified by western blot and real-time qPCR.

Conclusion: In this study, significant differences in the expression of signature genes were verified. The findings indicate that immature DCs with potential application value should be considered and high mutation sites of signature genes should be identified to reduce the occurrence of treatment resistance.

\section{INTRODUCTION}

Although malignant metastatic melanoma accounts for less than $5 \%$ of skin tumors, it causes the highest number of skin cancer-related deaths [1]. Thus, choosing the best treatment options is important. In recent years, an in-depth understanding of the pathogenesis of metastatic melanoma and the 
importance of the anti-tumor immune response and regulatory mechanism have provided melanoma patients with new treatment opportunities, which include targeted drug therapy and immune checkpoint inhibitors [2]. Nonetheless, chemotherapy remains the primary treatment for metastatic melanoma, and the inherent resistance of melanoma cells and incomplete response to chemotherapy drugs are major problems associated with melanoma treatment [3].

Many studies have explained the mechanism of gene mutation and methylation modification in the process of melanoma chemotherapy resistance [4, 5]. However, there are many artificial interference factors in the design of these studies, which cannot replicate the actual changes in tumors that occur in the natural environment and the final outcome of patients. There is also a lack of relevant reports on metastatic melanoma chemoresistance-related genes. Studies have shown that while chemotherapy kills tumor cells, it also stimulates the surrounding normal cells to release a chemical substance that can stimulate tumor cell growth and eventually lead to treatment resistance [6-8]. Therefore, exploring differences in gene expression in metastatic melanoma between chemotherapy and immunotherapy is not only helpful for improving our understanding of chemotherapy or immunotherapy resistance genes but also has guiding significance for the research and development of targeted therapy drugs.

\section{MATERIALS AND METHODS}

\section{Gene expression data acquisition and screening}

Data were collected according to the rules of public data use on official websites, and all normalized data were collected from The Cancer Genome Atlas data center (TCGA, https://portal.gdc.cancer.gov). Patients were screened based on the administration of chemotherapy (e.g., dacarbazine, cisplatin, etc.,) and immunotherapy (e.g., IL-2, interferon, etc.,). The exclusion criteria included samples with BRAF, NRAS, NF1, and KIT gene mutations and patients who were lost to follow-up.

\section{Differential gene analysis and screening}

After completing the grouping of samples (chemotherapy and immunotherapy), the fpackage (version 1.24) of $\mathrm{R}$ software (version 4.02, $\mathrm{R}$ Foundation for Statistical Computing, Vienna, Austria) was used to analyze the differences in gene expression between the two groups. The filter conditions for significant differences in gene expression were $|\log 2 \mathrm{FC}|$ $>1.5$ and $P<0.05$. Then, the STRING protein-protein interaction database was used to screen the key differential genes [9], and the filtering conditions in the
R package STRINGdb (version 2.30) were set to score $>500$ and connectivity $>2$.

Finally, the key screening method, Lasso regression and univariate Cox prognostic model were used. Due to the collinear relationship between the expression of certain genes, the constructed prognostic model exhibited overfitting. Lasso's penalty coefficient $(\lambda)$ was used to filter out the collinearity factors, and only the most representative factors were retained for the establishment of the prognosis model. The degree of Lasso regression complexity adjustment was controlled by the parameter $\lambda$. A greater value of $\lambda$ corresponds to a greater penalty to obtain a model with fewer variables from a complex model. In this study, the parameter $\lambda$ value was set to 1 , and the cutoff value was set to 0.6 in the R package glmnet (version 4.02).

\section{Analysis of the significance of signature genes}

This study focuses on the biological significance of the final screening of key genes and the difference in responsiveness to chemotherapy and immunotherapy. In addition, the mutation status and methylation changes of the signature genes were also influencing factors of chemotherapy tolerance. According to the clinical information, the chemotherapy and immunotherapy patients were matched based on the barcodes of patient samples in TCGA database. Therefore, this study also analyzed data on the mutation status, methylation changes and site information of signature genes, and all the data were downloaded from the TCGA database. $\mathrm{R}$ packages maftools [10] (version 2.0) and Gviz [11] (version 1.28) were used to compare gene mutation differences and map methylation site information, respectively.

\section{Verification of signature genes}

According to the standards of the Ethics Review Committee of Qingdao Municipal Hospital and the conditions of informed consent provided by the patients, skin tissue samples from twenty patients with metastatic MM who underwent chemotherapy and immunotherapy and ten normal patients were collected. According instructions of the western blotting techniques [12], relative protein concentration of signature genes in tissues was detected. All antibody reagents were purchased from Abcam (Abcam.com). The SYBR Green labeling method was used to detect the gene expression level of signature genes by real-time qPCR [13], and the gene amplification primer sequence was obtained from PrimerBank [14]. ABI StepOne Plus was used to calculate the relative expression differences of signature genes. The primers used in this study are listed in Supplementary Table 1. 


\section{Quantification and statistical analysis}

The western blot results of the signature genes were quantitatively analyzed by Quantity One (version 4.6.2, Bio-Rad Laboratories, Inc.,). The function of this tool can convert the gray value of the western blot image into data for comparative analysis. The real-time qPCR results were converted using the $2^{-\Delta \Delta c t}$ method to calculate the amplification fold changes, and Student's $t$-test was used to test whether the differences between the two groups were statistically significant $(P<0.05)$.

\section{RESULTS}

\section{Chemotherapy achieved a better overall survival expectancy}

According to the screening rules, the gene expression data of 46 patients with metastatic melanoma treated with chemotherapy and 47 patients with immunotherapy were ultimately used in this study. Table 1 shows the differences in the treatment period and response to chemotherapy or immunotherapy. The results showed that there was a significant difference in the response rate between the chemotherapy and immunotherapy patients. In addition, taking the final survival status (death or survival) as the outcome indicator, the cumulative overall survival and disease-specific survival events of patients in the chemotherapy group were significantly higher than those in the immunotherapy group (Figure 1A and 1B), whereas significant differences were not observed in progression-free survival (Figure 1C). The results also showed that there was no difference in overall survival between male and female patients (Figure 1D).

\section{Anti-tumor properties of signature genes}

Figure 2A shows the screening flowchart of signature genes, and based on $|\log 2 \mathrm{FC}|>1.5$ and $P<0.05,309$ DEGs were used to construct the PPI protein interaction network. Subsequently, the genes in the marginal region were filtered out according to score $>500$ and degree $>2$ of the protein molecule. In this result, 50 genes (Supplementary Table 2) were used to construct a generalized linear Lasso-Cox regression model to further remove genes with collinear characteristics. Finally, seven signature genes were obtained: $C C K B R, K C N J 11$, NMU, MMP13, ITGA10, IGFBP1 and CEACAM5.

According to The Cancer Immunome Atlas (TCIA) [15], a tumor immune cell infiltration analysis was performed, and the enrichment scores of these DEGs showed significant tumor suppressive effects in both the chemotherapy group and the immunotherapy group (Figure 2B). A comparison of the immune cell infiltration scores between the two groups showed that the immature dendritic cells (DCs) were significantly higher in the chemotherapy group than the immunotherapy group $(P<$ 0.01 ), while the central memory CD8 T cells and type 2 $\mathrm{T}$ helper cells were significantly higher in the immunotherapy group than the chemotherapy group $(P<$ 0.05) (Supplementary Figure 1A). The Pearson correlation test between immunoinfiltrating cells is shown in the attached Supplementary Figure 1B. In addition, these seven signature genes were divided into high and low groups according to their median expression levels. Significant anti-tumor effects were observed based on these groupings, and the high expression group of $C C K B R$ and $K C N J 11$ showed better anti-tumor effects (Supplementary Figure 1C).

\section{Functional enrichment in the PPI network}

The functional enrichment analyses of the 50 genes screened by the PPI network included gene ontology terms (cell composition, molecular function and biological process), pathways (KEGG and Reactome) and protein domains (InterPro and Ffam database). (Supplementary Figure 2A). The biological functions and effects of these key genes are shown in Supplementary Figure 2. The cell composition category mainly includes cell membrane synapses, keratin filaments, collagen trimers, cell junctions and ion channel complexes (Supplementary Figure 2B). The molecular function category mainly includes ion channel activity and receptor binding, such as cytokine activity and receptor binding function, chemokine activity and receptor binding function, collagen and hormone binding function, etc., (Supplementary Figure $2 \mathrm{C})$. The enrichment results of the integrated protein domains were mainly conserved sites of CXC chemokines, chemokine IL-8-like superfamily, hemopexin superfamily and intermediate filament (Supplementary Figure 2E). The signaling pathways mainly included IL-17, TNF and estrogen signaling, ECM, cytokine-cytokine and neuroactive-ligand receptor interactions, and nicotine and morphine addiction (Supplementary Figure 2F).

\section{Differences in the survival of signature genes}

As shown in Figure 2C, patients with high expression of the signature genes CCKBR, KCNJ11, ITGA10, and $I G F B P 1$ had higher overall survival prognoses while patients with low expression of $N M U, M M P 13$, and CEACAM5 had higher overall survival. This finding implies that patients with longer overall survival periods are positively correlated with anti-tumor scores for certain signature genes with high expression $(C C K B R$, $K C N J 11$, ITGA10, and IGFBPI) and other signature genes with low expression (NMU, MMP13 and 
Table 1. Characteristics of chemotherapy and immunotherapy patients.

\begin{tabular}{|c|c|c|c|c|}
\hline Group & Chemotherapy & Immunotherapy & $P$ (Stat) & Effect Size $(\mathbf{C I})^{\#}$ \\
\hline \multicolumn{5}{|l|}{ Observations $(N)$} \\
\hline & 46 & 47 & & \\
\hline \multicolumn{5}{|l|}{ Gender $\%(N)$} \\
\hline FEMALE & $33 \%(15)$ & $36 \%(17)$ & \multirow{3}{*}{$\begin{array}{l}0.89^{@} \\
(0.02)\end{array}$} & \multirow[t]{3}{*}{$0.86(0.33 ; 2.2)$} \\
\hline MALE & $67 \%(31)$ & $64 \%(30)$ & & \\
\hline missing & $0 \%(0)$ & $0 \%(0)$ & & \\
\hline \multicolumn{5}{|l|}{ Age at diagnosis (year) } \\
\hline Mean (SD) & $55(16)$ & $51(12)$ & \multirow{2}{*}{$\begin{array}{c}0.65^{\$} \\
(0.16)\end{array}$} & \multirow[t]{2}{*}{$0.28(-0.14 ; 0.7)$} \\
\hline valid (missing) & $45(1)$ & $45(2)$ & & \\
\hline \multicolumn{5}{|c|}{ Treatment response $\%$ (event) } \\
\hline Progressive Disease & $46 \%(21)$ & $21 \%(10)$ & \multirow{5}{*}{$\begin{array}{c}\mathbf{0 . 0 3 5}^{@} \\
(\mathbf{8 . 6})\end{array}$} & \multirow[t]{5}{*}{$0.39(0.15 ; 0.6)$} \\
\hline Complete Response & $17 \%(8)$ & $15 \%(7)$ & & \\
\hline Partial Response & $4.3 \%(2)$ & $6.4 \%(3)$ & & \\
\hline Stable Disease & $0 \%(0)$ & $11 \%(5)$ & & \\
\hline missing & $33 \%(15)$ & $47 \%(22)$ & & \\
\hline \multicolumn{5}{|l|}{ Days drug therapy (days) } \\
\hline Mean (SD) & $75(86)$ & $238(233)$ & \multirow{2}{*}{$\begin{array}{c}<0.001^{\$} \\
(0.46)\end{array}$} & \multirow[t]{2}{*}{$-0.94(-1.4 ;-0.45)$} \\
\hline valid (missing) & $38(8)$ & $35(12)$ & & \\
\hline \multicolumn{5}{|l|}{ OS \% (event) } \\
\hline Yes & $28 \%(13)$ & $55 \%(26)$ & \multirow{3}{*}{${ }_{(\mathbf{5 . 5})}^{\mathbf{. 0 1 9}^{@}}$} & \multirow[t]{3}{*}{$0.33(0.13 ; 0.84)$} \\
\hline No & $70 \%(32)$ & $45 \%(21)$ & & \\
\hline missing & $2.2 \%(1)$ & $0 \%(0)$ & & \\
\hline \multicolumn{5}{|l|}{ OS.time (days) } \\
\hline Mean (SD) & $1.8 \mathrm{e}+03(1.8 \mathrm{e}+03)$ & $2.4 \mathrm{e}+03(1.9 \mathrm{e}+03)$ & \multirow{2}{*}{$\begin{array}{l}0.24^{\$} \\
(0.22)\end{array}$} & \multirow[t]{2}{*}{$-0.34(-0.76 ; 0.085)$} \\
\hline valid (missing) & $45(1)$ & $44(3)$ & & \\
\hline \multicolumn{5}{|l|}{ DSS \% (event) } \\
\hline Yes & $33 \%(15)$ & $62 \%(29)$ & \multirow{3}{*}{${ }_{(\mathbf{6 . 3})}^{\mathbf{0 . 0 1 2}}$} & \multirow[t]{3}{*}{$0.31(0.12 ; 0.79)$} \\
\hline No & $65 \%(30)$ & $38 \%(18)$ & & \\
\hline missing & $2.2 \%(1)$ & $0 \%(0)$ & & \\
\hline \multicolumn{5}{|l|}{ DSS.time (days) } \\
\hline Mean (SD) & $1.8 \mathrm{e}+03(1.8 \mathrm{e}+03)$ & $2.4 \mathrm{e}+03(1.9 \mathrm{e}+03)$ & \multirow{2}{*}{$\begin{array}{c}0.24^{\$} \\
(0.22)\end{array}$} & \multirow[t]{2}{*}{$-0.34(-0.76 ; 0.085)$} \\
\hline valid (missing) & $45(1)$ & $44(3)$ & & \\
\hline \multicolumn{5}{|l|}{ PFI \% (event) } \\
\hline Yes & $11 \%(5)$ & $23 \%(11)$ & \multirow{3}{*}{$\begin{array}{l}0.2^{@} \\
(1.6)\end{array}$} & $0.41(0.1 ; 1.4)$ \\
\hline No & $87 \%(40)$ & $77 \%(36)$ & & \\
\hline missing & $2.2 \%(1)$ & $0 \%(0)$ & & \\
\hline PFI.time (days) & & & & \\
\hline Mean (SD) & $1.3 e+03(1.7 e+03)$ & $1.5 e+03(1.6 e+03)$ & $0.33^{\$}$ & $-0.14(-0.56 ; 0.28)$ \\
\hline valid (missing) & $45(1)$ & $45(2)$ & $(0.2)$ & \\
\hline
\end{tabular}

"Effect size is calculated by Cohen's d statistics. ${ }^{@} P$ value and statistic result are calculated by Chi-sq.test. ${ }^{\$} P$ value and statistic result are calculated by ANOVA. Abbreviations: $\mathrm{Cl}$ : confidential interval; OS: overall survival; DSS: disease specific survival; PFI: progression free interval.

CEACAM5). However, based on the anti-tumor properties described above, this property was significant only in the signature genes CCKBR and KCNJ11 (Supplementary Figure 1). 
Then, receiver operating characteristic curves (ROCs) of these signature genes were drawn, and the area under the curve (AUC) was used to indicate the predictive value of the model. As shown in Figure 2D, the AUC values of the CCKBR, KCNJ11, $N M U$ and $M M P 13$ genes were greater than 0.7 and the AUC values of the other signature genes were between 0.7 and 0.6. In addition, the sensitivity, specificity and accuracy of the seven characteristic genes were also calculated to evaluate the predictive value of the signature genes in the ROC model.

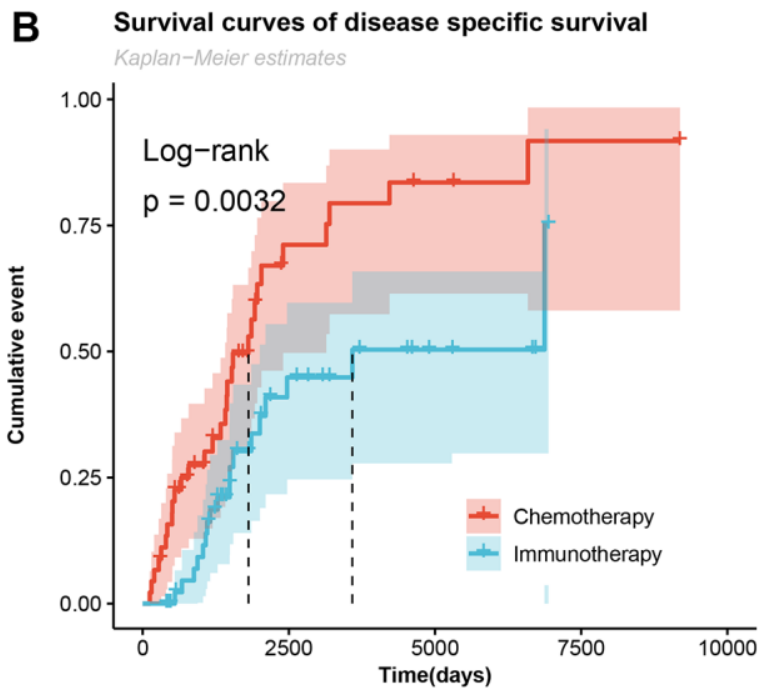

Cumulative number of events
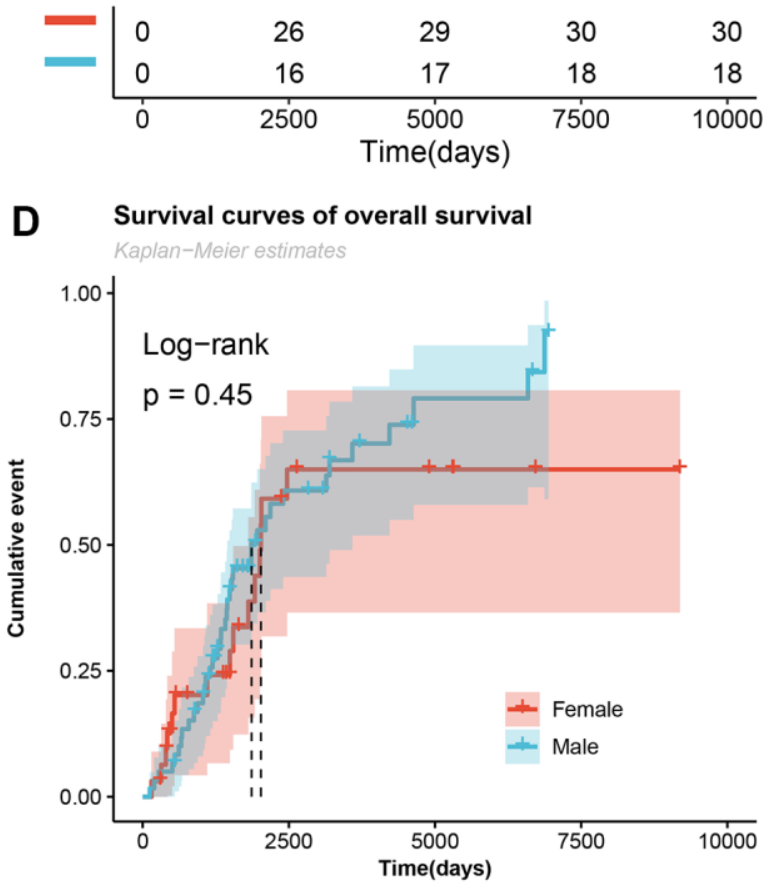

Cumulative number of events

\begin{tabular}{ccccc}
0 & 15 & 15 & 15 & 15 \\
0 & 31 & 36 & 38 & 38 \\
\hline 0 & 2500 & 5000 & 7500 & 10000 \\
& & Time(days) & &
\end{tabular}

Figure 1. Cumulative number of survived events in patients with metastatic melanoma undergoing chemotherapy and immunotherapy. (A-C) The Log-rank test for overall survival, disease specific survival, and progression-free interval survival curves of the chemotherapy and immunotherapy groups. (D) Survival curves of overall survival of male and female patients. 


\section{Differences in mutations, methylation and treatment response}

The signature genes CEACAM5, ITGA10 and MMP13 had the highest proportion of mutations among all 467 patients with cutaneous melanoma of the skin (Figure $3 \mathrm{~A}$ and $3 \mathrm{~B}$ ). Although the frequency of mutations in the immunotherapy group was higher than that in the chemotherapy group, no significant difference was found between the two groups because the total
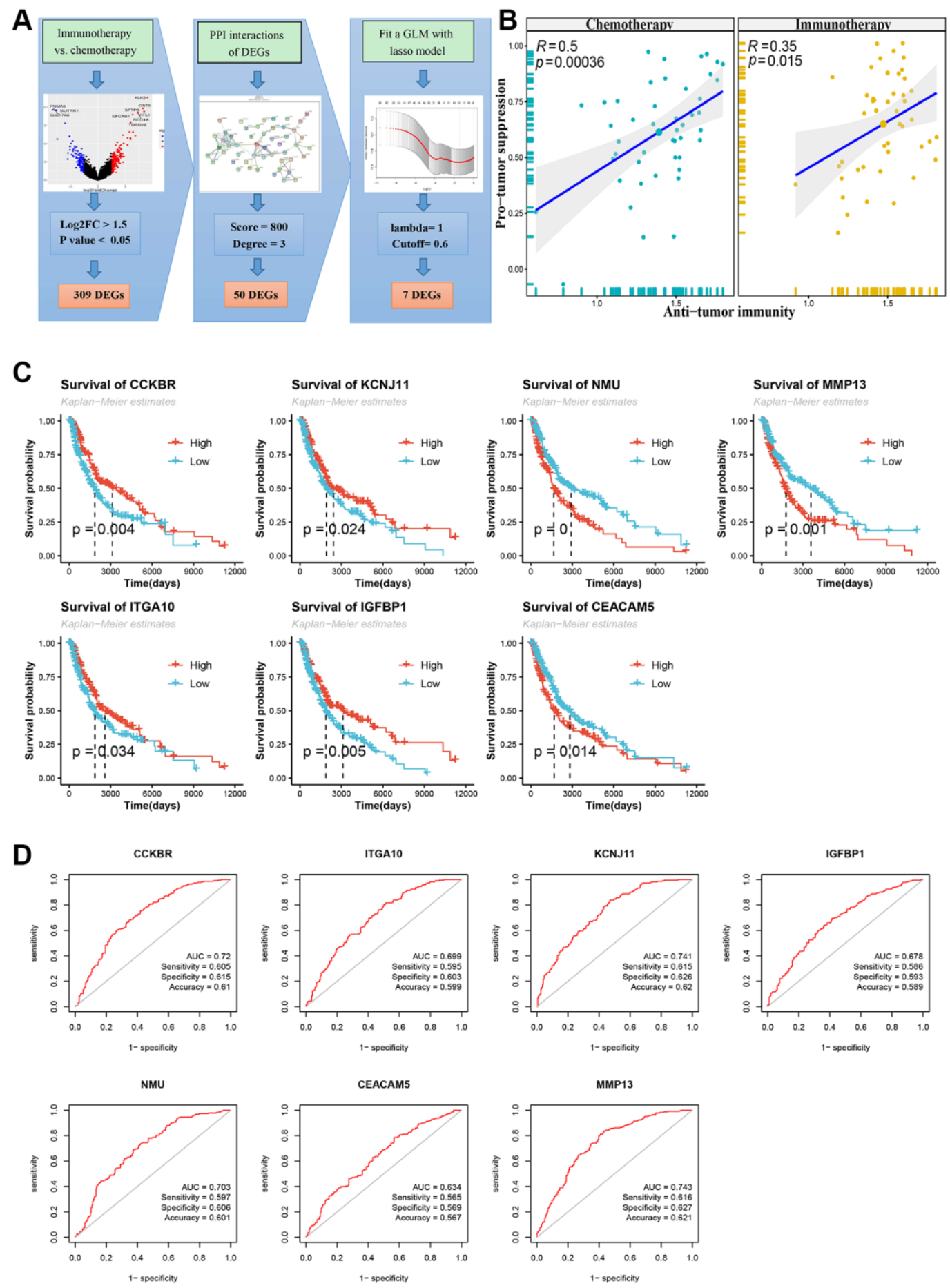

Figure 2. Flowchart of screening signature genes and its Kaplan-Meier survival curve and receiver operating characteristic curve (ROC). (A) Flowchart of screening signature genes. Including volcano plot of differentially expressed genes (DEGs), DEGs' PPI network and Lasso-COX fitting model. (B) DEGs immune cell infiltration analysis, Pearson correlation test of Anti-tumor and Pro-tumor suppression based on immune cell type enrichment scores. (C) Log-rank test for survival curves of signature genes. (D) ROC curve, area under curve (AUC), sensitivity, specificity and accuracy values of signature genes. 
sample of the study was only 93 cases (Figure 3C). A comparison of the protein domains of the missense mutations showed that the protein domains of the immunotherapy group mainly occurred in the boxlabeled region while those of the chemotherapy group mainly occurred outside the box-labeled region.
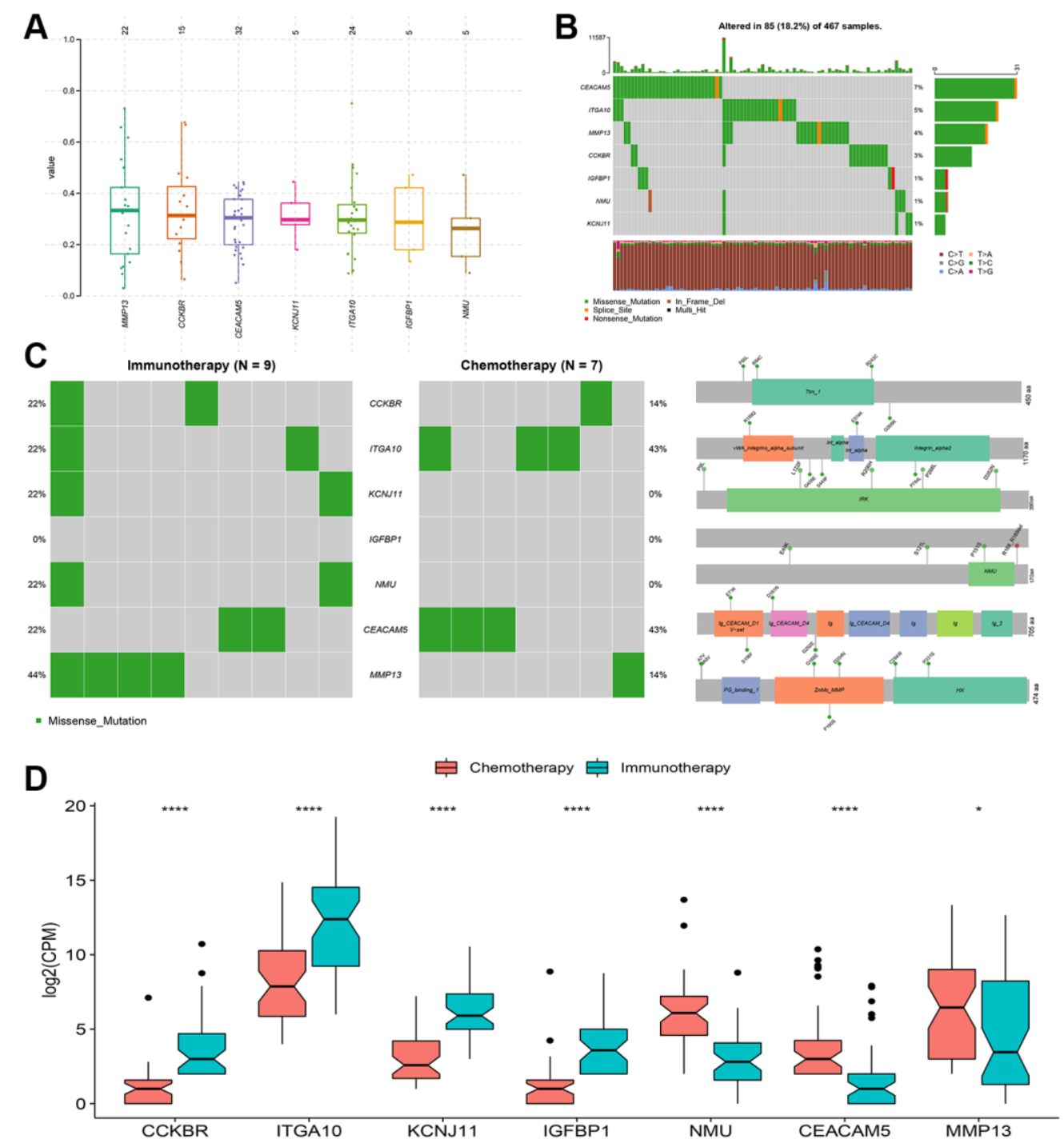

E

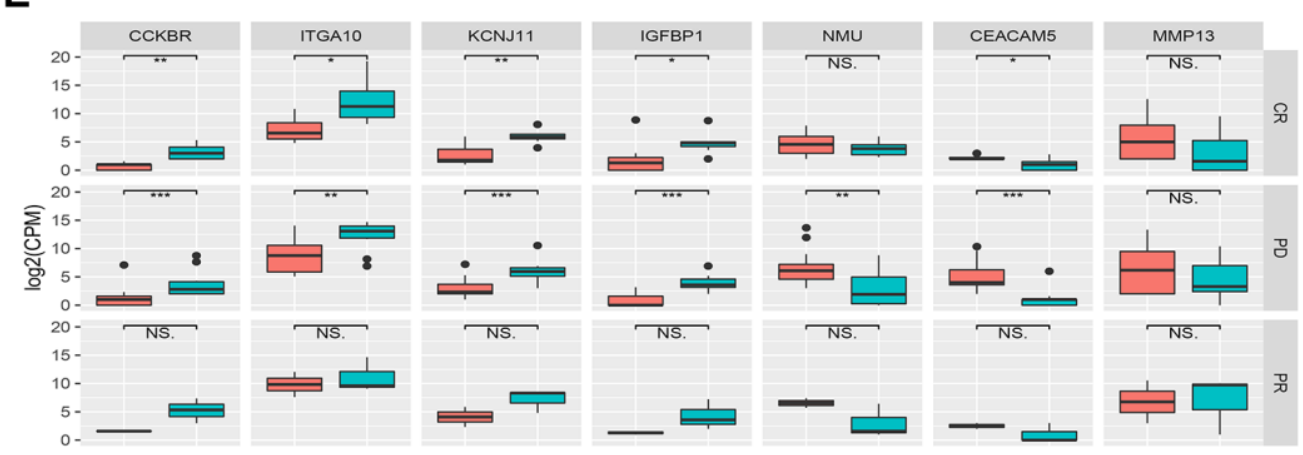

Figure 3. Genetic variation and relative expression differences of signature genes between chemotherapy and immunotherapy. (A and B) Mutation frequency and type of signature genes. (C) Mutations and protein domain differences of signature genes between chemotherapy group and immunotherapy group. (D) Differences in relative expression levels (log2(CPM)) of signature genes between the two groups. (E) Comparison of complete response (CR), partial response (PR) and progressive disease (PD) differences in signature genes between the two groups. ${ }^{*} P<0.05,{ }^{* *} P<0.01,{ }^{* * *} P<0.001,{ }^{* * * *} P<0.0001$, NS: no significance. 
Treatment responses include complete response, partial response, and disease progression, which are important indicators for judging the effectiveness of tumor treatment. Based on significant differences in signature genes between the two treatment groups (Figure 3D), they were grouped according to the treatment response, and significant differences in disease progression were observed for all genes except for the MMP13 gene and differences in complete response were mainly observed for the CCKBR, KCNJ11, ITGA10, IGFBPI and CEACAM5 genes (Figure 3E). No significant differences were found for partial responses.

In addition, a group comparison was performed for methylation site changes of these signature genes. Significant differences were not found between the chemotherapy group and the immunotherapy group or between the treatment response groups. The comparative results are shown in Supplementary Figure 3.

\section{Expression changes of signature genes in metastatic melanoma tissues}

Using basic public data, this study verified the expression changes of signature genes in patients with metastatic melanoma after chemotherapy and immunotherapy. The gene expression level and protein concentration were expressed using real-time qPCR and western blotting, respectively, with reference to the relative expression level of the internal control. As shown in Figure 4A-4B, the comparison of the relative protein concentration of characteristic gene expression showed that the protein concentrations of CCKBR, ITGA10 and IGFBP1 in melanoma tumor tissue in the postoperative chemotherapy group were significantly higher than those in the immunotherapy group while the protein concentrations of KCNJ11, NMU, MMP13 and CEACAM5 in the chemotherapy group were significantly lower than those in the immunotherapy group. In addition, the relative differences in gene expression levels (Figure 4C) were consistent with the results of previous data analysis (Figure 3D). It is worth noting that the difference in protein concentration expressed by the KCNJ11 gene is opposite to the difference in gene expression level. Additionally, the hematoxylin-eosin (HE) staining results showed that the skin tissue structure of tumor patients was disordered and deeply stained compared with that of normal individuals (Figure 4D).

\section{DISCUSSION}

It is generally believed that melanoma is an immunogenic cancer and immunotherapy, with its potential therapeutic effects, may theoretically resolve the deficiency of tumor chemotherapy resistance. However, in this study, patients with metastatic melanoma who received immunotherapy did not obtain a longer overall survival and progressionfree interval and in fact experienced a higher mortality rate caused by specific diseases. In addition, studies have evaluated the use of immunotherapy based on interferon alfa-2b [16, 17] and high-dose IL-2 [18] to treat metastatic melanoma; however, the results were not as effective as in theory. Four prospective trials in Atkins' observation study [16] showed that in patients with highrisk resection of melanoma, adjuvant therapy with highdose interferon-alpha- $2 b$ can effectively improve the relapse-free survival rate but not the overall survival rate. Moreover, this therapeutic effect only occurred in patients older than 46 years of age in two prospective studies, and significant differences were not observed in the combined result. In the case of a combination of many melanoma treatment methods (such as cocktail therapy), in which one or a combination plays a key role, it is difficult to obtain a fixed answer under different circumstances. For example, in a randomized phase III trial of combination chemoimmunotherapy (dacarbazine, cisplatin, and interferon-alpha-2b) with or without IL-2 as adjuvant therapy, the results did not show a significant improvement in progression-free survival or the treatment response rate in patients with metastatic melanoma [19].

Similar to the differences in immune cell infiltration observed earlier in this study, immature DCs have strong antigen-phagocytosis ability and differentiate into mature DCs when they ingest antigens or are stimulated by certain factors [20], while mature DCs express high levels of costimulators and adhesion factors [21]. A recent study showed that treatment with immature dendritic cell-targeted vaccines significantly improved the survival rate in murine melanoma models, and this improved efficacy was positively correlated with tumor lysate gene expression levels and tumorinfiltrating lymphocytes (TILs) [22]. Appropriate chemotherapy is not only the main method of killing immature cells and proliferating active cells but can also produce abundant antigens to activate a large number of immature DCs. Immature DCs, as the most functional APC found thus far, can acquire the initiation ability of specific cytotoxic $\mathrm{T}$ lymphocytes (CTLs) under independent or dependent induction of $\mathrm{T}$ helper cells [23]. In addition, a DC-based immunotherapy vaccine (Sipuleucel-T) for prostate cancer was approved for use by the FDA in 2010 [24, 25].

Growing evidence has shown that tumors progress slowly over a long period of time before they manifest as a distinct disease. According to a recent study by Harvard Medical School and others, the initial cancer-causing mutation may have appeared as early as 40 years ago, at least in some cases [26]. This finding 
seems slightly alarmist, although it provides sufficient warning of the importance of tumor diseases. After all, many deaths are caused by tumors every year, with 1.76 million new cancer cases and 600,000 cancer deaths in the United States in 2019 [27] and an estimated 4.3 million new cancer cases and 2.9 million cancer deaths in China in 2018 [28]. Moreover, certain deaths caused by tumor diseases (such as lung cancer and colorectal cancer) have a tendency to increase annually, especially in low-income countries [29]. Detection of mutant genes and $\mathrm{CpG}$ methylation is of great significance to the selection of targeted therapy for patients, and it is also the main reason for immunotherapy resistance [4, 5]. Although significant differences in signature gene mutations and $\mathrm{CpG}$ methylation were not observed between the two treatment groups, it is undeniable that mutations and methylation occurred and may play an important role in the development of melanoma and the exploration of new treatment methods.

Tumor genesis is characterized by a series of complex and persistent environmental factors. According to the functional enrichment results of the 50 key genes screened by PPI in this study, systemic treatment not
A
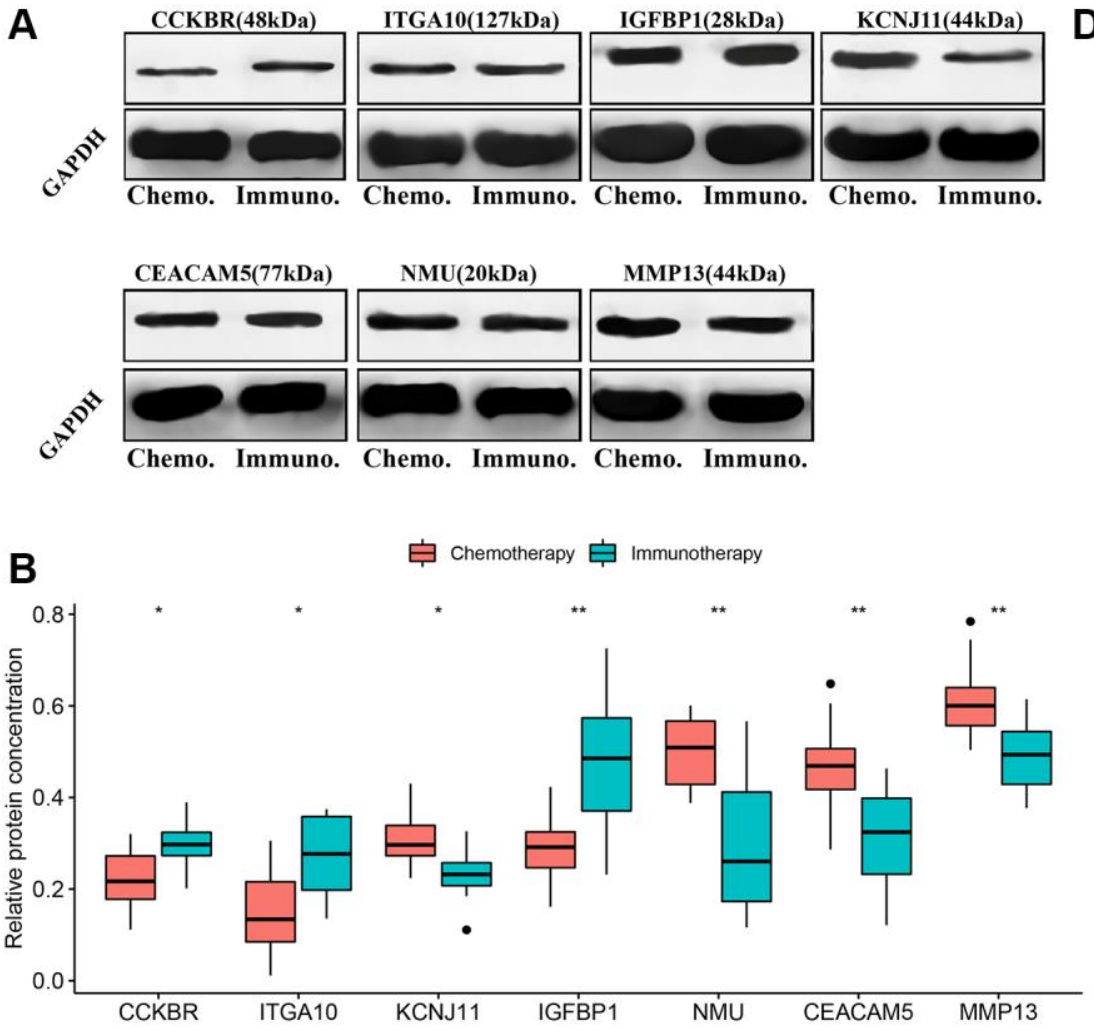

C

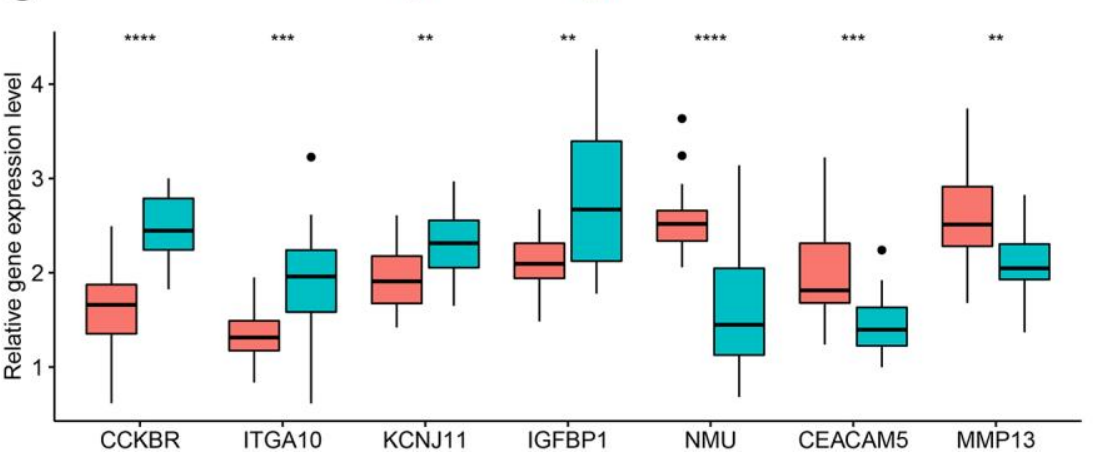

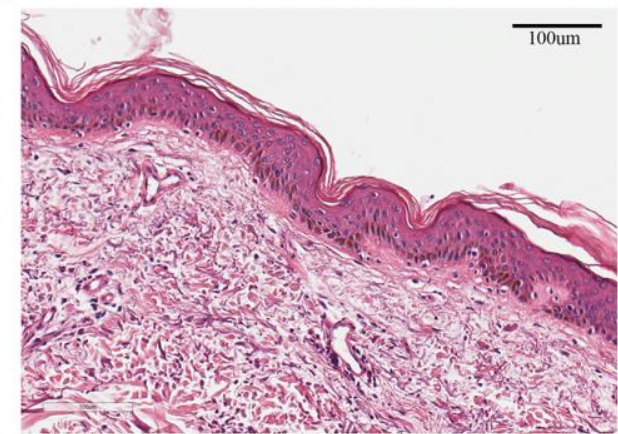

Normal skin tissue
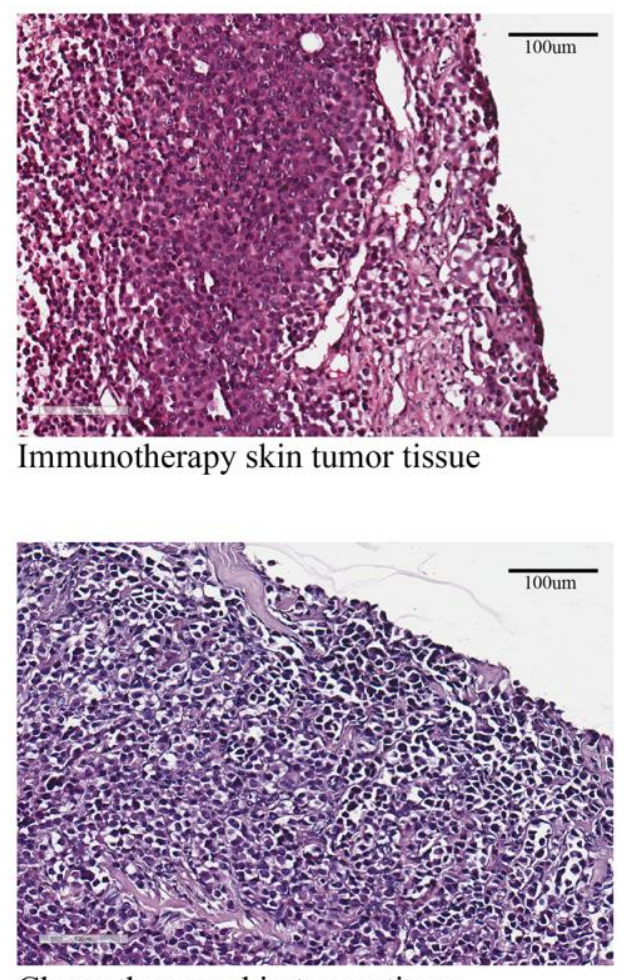

Chemotherapy skin tumor tissue

Figure 4. Validation of signature genes in patients with metastatic cutaneous melanoma undergoing chemotherapy and immunotherapy. (A and $\mathbf{B}$ ) Western blot results of signature genes and $t$-test comparison results of gray values between the two groups. (C) $T$-test comparison results of the relative expression levels of signature genes in real-time qPCR between the two groups. (D) Hematoxylineosin (HE) staining: normal skin tissue, tumor tissues of metastatic melanoma patients receiving chemotherapy and immunotherapy. ${ }^{*} P<$ $0.05,{ }^{* *} P<0.01,{ }^{* * *} P<0.001,{ }^{* * * *} P<0.0001$. 
only induces changes in the basic functions and activities of cells (e.g., membrane synapses, ion channel complexes, etc.,) but also leads to abnormalities in the immune and endocrine systems (e.g., cytokines/chemokines, TNF and estrogen signaling). Subsequently, researchers have proposed a new tumor treatment method: combination therapy targeting the tumor microenvironment [30]. TIL infusion, as a new immunomodulatory strategy, was approved for clinical use by the FDA in 2019 and can effectively extend the lives of patients with advanced cancer. The number of infused cells was related to a good response. This strategy has been applied for patients with metastatic melanoma [31, 32] and can be used as an alternative therapy after the failure of immune checkpoint inhibitor therapy [33]. Solid tumors that are highly infiltrated with immune cells and proinflammatory cytokines have been classified as inflammatory tumors [34].

The tumor microenvironment is an environment composed of malignant cells, normal cells, immune components, blood vessels, ECM, and other molecules. These components can work alone and jointly to affect sensitivity to chemotherapy or immunotherapy. As new immunomodulatory treatments and technological innovations continue to advance the field of cancer immunotherapy, the goal of personalized medicine seems to have become a reality. From single reagents to systemic treatment (including physical, chemical, biological and immunotherapy), almost every treatment strategy is associated with a study claiming that it prolongs the survival time of patients. However, almost all patients are ultimately defeated by the tumor or the side effects, which has led to many questions about the effectiveness of cancer treatment. Thus, with all these advanced treatments, one may wonder why a significant reduction in cancer deaths has not occurred. Perhaps God knows the answer.

In short, huge challenges remain in exploring the most effective method for treating advanced melanoma, and this journey remains full of possibilities. In addition to the difficulties mentioned above, this study not only explores and verifies the differences in the expression of signature genes in patients with metastatic melanoma who received either chemotherapy or immunotherapy but also provides insights into differences in signature gene in terms of biological function, gene mutation frequency, protein domain, and $\mathrm{CpG}$ methylation level. These findings could provide important clues for the discovery of new tumor immunotherapy strategies.

\section{AUTHOR CONTRIBUTIONS}

Conceptualization: Yang Li, Yuling Gao; Data collection and analysis: Weiling Chu, Jianjian Lv, Zhi Li; Methodology: Yang Li, Weiling Chu; Visualization:
Yang Li, Jianjian Lv; Writing: Yang Li, Yuling Gao, Zhi

Li; Review and editing: Tongxin Shi, Zhi Li, Jianjian Lv.

\section{CONFLICTS OF INTEREST}

The authors declare no conflicts of interest related to this study.

\section{FUNDING}

This work is partially supported by the Class B of Qingdao Medical and Health Key Discipline Construction Project: 2020-2023 and Qingdao Medical and Health Outstanding Young Talent Training Project: 2020-2023. The founders had no role in study design, data collection and analysis, decision to publish, or preparation of the manuscript.

\section{REFERENCES}

1. Mishra H, Mishra PK, Ekielski A, Jaggi M, lqbal Z, Talegaonkar S. Melanoma treatment: from conventional to nanotechnology. J Cancer Res Clin Oncol. 2018; 144:2283-302.

https://doi.org/10.1007/s00432-018-2726-1 PMID: $\underline{30094536}$

2. Pasquali S, Chiarion-Sileni V, Rossi CR, Mocellin S. Immune checkpoint inhibitors and targeted therapies for metastatic melanoma: A network meta-analysis. Cancer Treat Rev. 2017; 54:34-42.

https://doi.org/10.1016/i.ctrv.2017.01.006

PMID:28189914

3. Gide TN, Wilmott JS, Scolyer RA, Long GV. Primary and Acquired Resistance to Immune Checkpoint Inhibitors in Metastatic Melanoma. Clin Cancer Res. 2018; 24:1260-70.

https://doi.org/10.1158/1078-0432.CCR-17-2267 PMID:29127120

4. Zaretsky JM, Garcia-Diaz A, Shin DS, Escuin-Ordinas H, Hugo W, Hu-Lieskovan S, Torrejon DY, Abril-Rodriguez G, Sandoval S, Barthly L, Saco J, Homet Moreno B, Mezzadra R, et al. Mutations Associated with Acquired Resistance to PD-1 Blockade in Melanoma. N Engl J Med. 2016; 375:819-29. https://doi.org/10.1056/NEJMoa1604958 PMID:27433843

5. Emran AA, Chatterjee A, Rodger EJ, Tiffen JC, Gallagher SJ, Eccles MR, Hersey P. Targeting DNA Methylation and EZH2 Activity to Overcome Melanoma Resistance to Immunotherapy. Trends Immunol. 2019; 40:328-44. https://doi.org/10.1016/j.it.2019.02.004 PMID:30853334

6. Sun Y, Campisi J, Higano C, Beer TM, Porter P, Coleman I, True L, Nelson PS. Treatment-induced 
damage to the tumor microenvironment promotes prostate cancer therapy resistance through WNT16B. Nat Med. 2012; 18:1359-68.

https://doi.org/10.1038/nm.2890

PMID:22863786

7. Johnson LM, Price DK, Figg WD. Treatment-induced secretion of WNT16B promotes tumor growth and acquired resistance to chemotherapy: implications for potential use of inhibitors in cancer treatment. Cancer Biol Ther. 2013; 14:90-91.

https://doi.org/10.4161/cbt.22636

PMID:23114711

8. Ostman A. The tumor microenvironment controls drug sensitivity. Nat Med. 2012; 18:1332-34.

https://doi.org/10.1038/nm.2938

PMID:22961158

9. Szklarczyk D, Franceschini A, Wyder S, Forslund K, Heller D, Huerta-Cepas J, Simonovic M, Roth A, Santos A, Tsafou KP, Kuhn M, Bork P, Jensen LJ, von Mering C. STRING v10: protein-protein interaction networks, integrated over the tree of life. Nucleic Acids Res. 2015; 43:D447-52.

https://doi.org/10.1093/nar/gku1003

PMID:25352553

10. Mayakonda A, Lin DC, Assenov Y, Plass C, Koeffler HP. Maftools: efficient and comprehensive analysis of somatic variants in cancer. Genome Res. 2018; 28:1747-56.

https://doi.org/10.1101/gr.239244.118 PMID:30341162

11. Hahne F, Ivanek R. Visualizing Genomic Data Using Gviz and Bioconductor. Methods Mol Biol. 2016; 1418:335-51.

https://doi.org/10.1007/978-1-4939-3578-9 16

PMID:27008022

12. Kurien BT, Scofield RH. Western blotting: an introduction. Methods Mol Biol. 2015; 1312:17-30. https://doi.org/10.1007/978-1-4939-2694-7 5 PMID:26043986

13. Navarro E, Serrano-Heras G, Castaño MJ, Solera J. Real-time PCR detection chemistry. Clin Chim Acta. 2015; 439:231-50.

https://doi.org/10.1016/i.cca.2014.10.017 PMID:25451956

14. Wang X, Spandidos A, Wang H, Seed B. PrimerBank: a PCR primer database for quantitative gene expression analysis, 2012 update. Nucleic Acids Res. 2012; 40:D1144-49.

https://doi.org/10.1093/nar/gkr1013

PMID:22086960

15. Charoentong $P$, Finotello $F$, Angelova $M$, Mayer C, Efremova M, Rieder D, Hackl H, Trajanoski Z. Pan- cancer Immunogenomic Analyses Reveal GenotypeImmunophenotype Relationships and Predictors of Response to Checkpoint Blockade. Cell Rep. 2017; 18:248-62.

https://doi.org/10.1016/j.celrep.2016.12.019

PMID:28052254

16. Kirkwood JM, Manola J, Ibrahim J, Sondak V, Ernstoff MS, Rao U, and Eastern Cooperative Oncology Group. A pooled analysis of eastern cooperative oncology group and intergroup trials of adjuvant high-dose interferon for melanoma. Clin Cancer Res. 2004; 10:1670-77.

https://doi.org/10.1158/1078-0432.ccr-1103-3 PMID: 15014018

17. Kirkwood JM, Strawderman MH, Ernstoff MS, Smith TJ, Borden EC, Blum RH. Interferon alfa-2b adjuvant therapy of high-risk resected cutaneous melanoma: the Eastern Cooperative Oncology Group Trial EST 1684. J Clin Oncol. 1996; 14:7-17.

https://doi.org/10.1200/JCO.1996.14.1.7

PMID:8558223

18. Atkins $M B$, Lotze MT, Dutcher JP, Fisher RI, Weiss G, Margolin K, Abrams J, Sznol M, Parkinson D, Hawkins M, Paradise C, Kunkel L, Rosenberg SA. High-dose recombinant interleukin 2 therapy for patients with metastatic melanoma: analysis of 270 patients treated between 1985 and 1993. J Clin Oncol. 1999; 17:2105-16. https://doi.org/10.1200/JCO.1999.17.7.2105 PMID: 10561265

19. Keilholz U, Punt CJ, Gore M, Kruit W, Patel P, Lienard D, Thomas J, Proebstle TM, Schmittel A, Schadendorf $D$, Velu T, Negrier S, Kleeberg $U$, et al. Dacarbazine, cisplatin, and interferon-alfa-2b with or without interleukin-2 in metastatic melanoma: a randomized phase III trial (18951) of the European Organisation for Research and Treatment of Cancer Melanoma Group. J Clin Oncol. 2005; 23:6747-55.

https://doi.org/10.1200/JCO.2005.03.202 PMID: 16170182

20. Um E, Oh JM, Park J, Song T, Kim TE, Choi Y, Shin C, Kolygina D, Jeon JH, Grzybowski BA, Cho YK. Immature dendritic cells navigate microscopic mazes to find tumor cells. Lab Chip. 2019; 19:1665-75. https://doi.org/10.1039/c9lc00150f PMID:30931468

21. Tiberio L, Del Prete A, Schioppa T, Sozio F, Bosisio D, Sozzani S. Chemokine and chemotactic signals in dendritic cell migration. Cell Mol Immunol. 2018; 15:346-52.

https://doi.org/10.1038/s41423-018-0005-3 PMID:29563613

22. Gordy JT, Luo K, Kapoor A, Kim ES, Ayeh SK, Karakousis PC, Markham RB. Treatment with an 
immature dendritic cell-targeting vaccine supplemented with IFN- $\alpha$ and an inhibitor of DNA methylation markedly enhances survival in a murine melanoma model. Cancer Immunol Immunother. 2020; 69:569-80.

https://doi.org/10.1007/s00262-019-02471-0

PMID: 31980915

23. Schuurhuis DH, Laban $\mathrm{S}$, Toes RE, Ricciardi-Castagnoli P, Kleijmeer MJ, van der Voort El, Rea D, Offringa R, Geuze HJ, Melief CJ, Ossendorp F. Immature dendritic cells acquire CD8(+) cytotoxic $T$ lymphocyte priming capacity upon activation by $\mathrm{T}$ helper cell-independent or-dependent stimuli. J Exp Med. 2000; 192:145-50. https://doi.org/10.1084/jem.192.1.145 PMID:10880536

24. Pan RY, Chung WH, Chu MT, Chen SJ, Chen HC, Zheng L, Hung SI. Recent Development and Clinical Application of Cancer Vaccine: Targeting Neoantigens. J Immunol Res. 2018; 2018:4325874. https://doi.org/10.1155/2018/4325874 PMID:30662919

25. Kantoff PW, Higano CS, Shore ND, Berger ER, Small EJ, Penson DF, Redfern $\mathrm{CH}$, Ferrari AC, Dreicer $\mathrm{R}$, Sims RB, Xu Y, Frohlich MW, Schellhammer PF, and IMPACT Study Investigators. Sipuleucel-T immunotherapy for castration-resistant prostate cancer. N Engl J Med. 2010; 363:411-22.

https://doi.org/10.1056/NEJMoa1001294

PMID:20818862

26. Van Egeren D, Escabi J, Nguyen M, Liu S, Reilly CR, Patel S, Kamaz B, Kalyva M, DeAngelo DJ, Galinsky I, Wadleigh M, Winer ES, Luskin MR, et al. Reconstructing the Lineage Histories and Differentiation Trajectories of Individual Cancer Cells in Myeloproliferative Neoplasms. Cell Stem Cell. 2021; 28:514-23.e9.

https://doi.org/10.1016/j.stem.2021.02.001 PMID:33621486

27. Siegel RL, Miller KD, Jemal A. Cancer statistics, 2019. CA Cancer J Clin. 2019; 69:7-34. https://doi.org/10.3322/caac.21551 PMID:30620402
28. Feng RM, Zong YN, Cao SM, Xu RH. Current cancer situation in China: good or bad news from the 2018 Global Cancer Statistics? Cancer Commun (Lond). 2019; 39:22.

https://doi.org/10.1186/s40880-019-0368-6

PMID:31030667

29. DeSantis CE, Miller KD, Goding Sauer A, Jemal A, Siegel RL. Cancer statistics for African Americans, 2019. CA Cancer J Clin. 2019; 69:211-33.

https://doi.org/10.3322/caac.21555

PMID: 30762872

30. Murciano-Goroff YR, Warner AB, Wolchok JD. The future of cancer immunotherapy: microenvironmenttargeting combinations. Cell Res. 2020; 30:507-19. https://doi.org/10.1038/s41422-020-0337-2 PMID: $\underline{32467593}$

31. Lee N, Zakka LR, Mihm MC Jr, Schatton T. Tumourinfiltrating lymphocytes in melanoma prognosis and cancer immunotherapy. Pathology. 2016; 48:177-87. https://doi.org/10.1016/i.pathol.2015.12.006 PMID:27020390

32. Lee S, Margolin K. Tumor-infiltrating lymphocytes in melanoma. Curr Oncol Rep. 2012; 14:468-74. https://doi.org/10.1007/s11912-012-0257-5 PMID:22878966

33. Dafni U, Michielin O, Lluesma SM, Tsourti Z, Polydoropoulou V, Karlis D, Besser MJ, Haanen J, Svane IM, Ohashi PS, Kammula US, Orcurto A, Zimmermann $S$, et al. Efficacy of adoptive therapy with tumor-infiltrating lymphocytes and recombinant interleukin-2 in advanced cutaneous melanoma: a systematic review and meta-analysis. Ann Oncol. 2019; 30:1902-13. https://doi.org/10.1093/annonc/mdz398 PMID: 31566658

34. Chen DS, Mellman I. Elements of cancer immunity and the cancer-immune set point. Nature. 2017; 541:321-30. https://doi.org/10.1038/nature21349 PMID:28102259 


\section{SUPPLEMENTARY MATERIALS}

\section{Supplementary Figures}
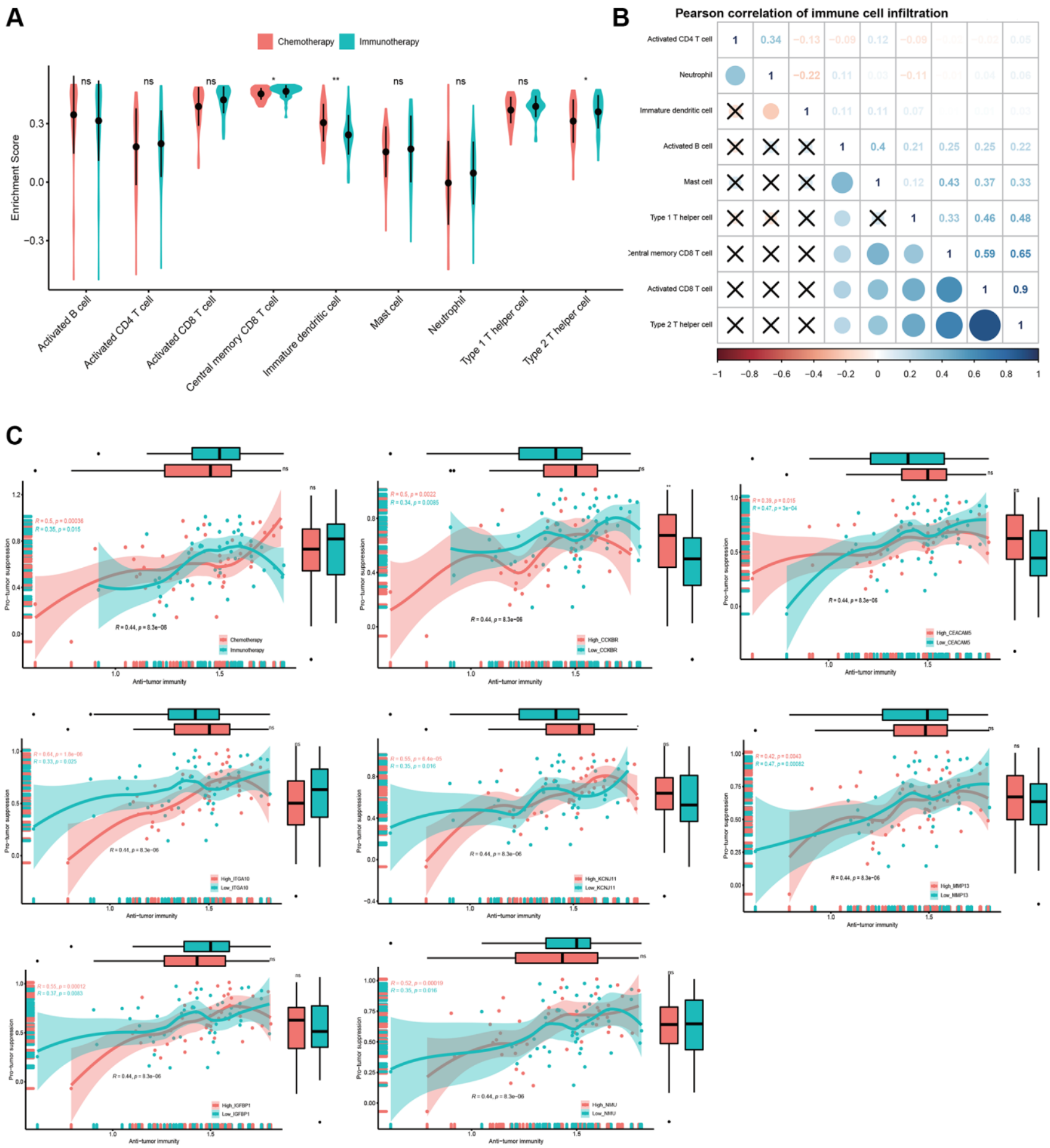

Supplementary Figure 1. Difference in DEGs-based immune cell infiltration. (A) Immune cell infiltration difference between chemotherapy and immunotherapy groups. (B) Pearson correlation of immune cell infiltration enrichment score. (C) Immune cell infiltration difference between low expression group and high expression group of signature genes. 

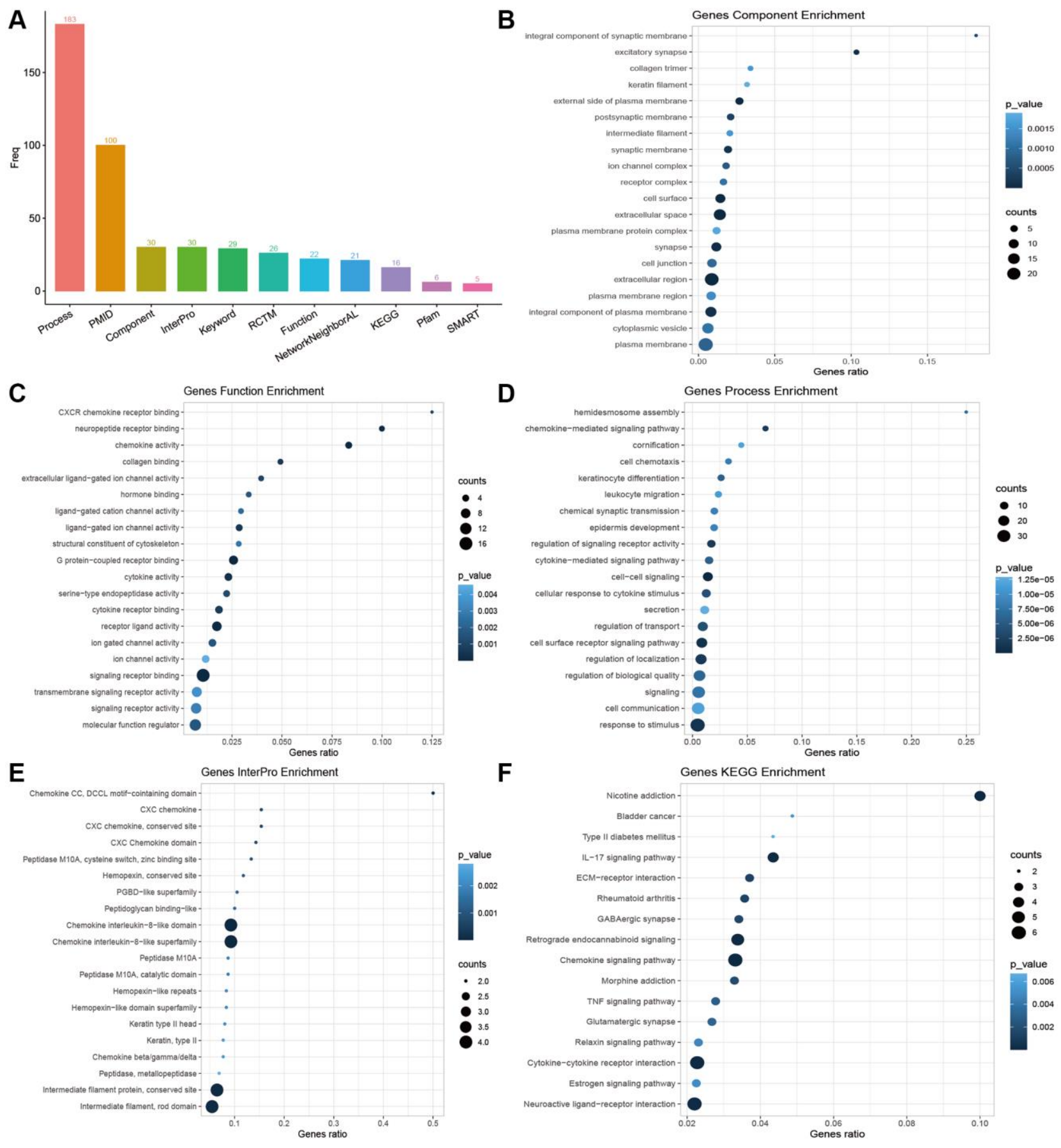

Supplementary Figure 2. Enrichment map of $\mathbf{5 0}$ important genes screened by PPI network. (A) Enrichment results of different functional distribution. (B-F) Dotplot of top 20 items in the enrichment results of cell composition, molecular function, biological process, integrated protein domains and KEGG pathway. 

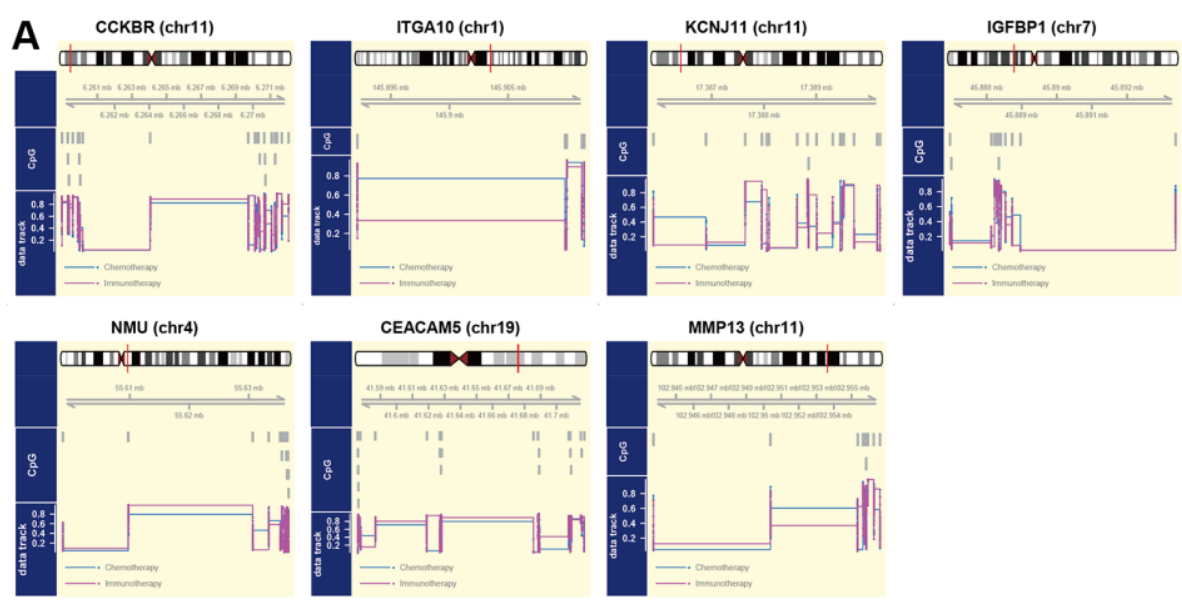

CEACAM5 (chr19)

MMP13 (chr11)
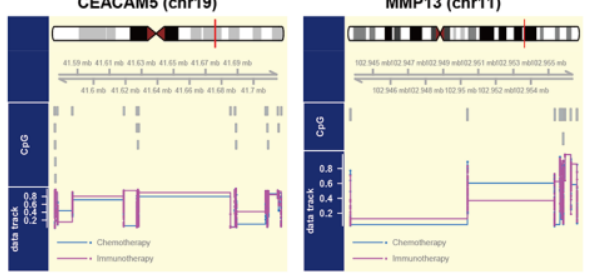

B

官 Chemotherapy 追 Immunotherapy

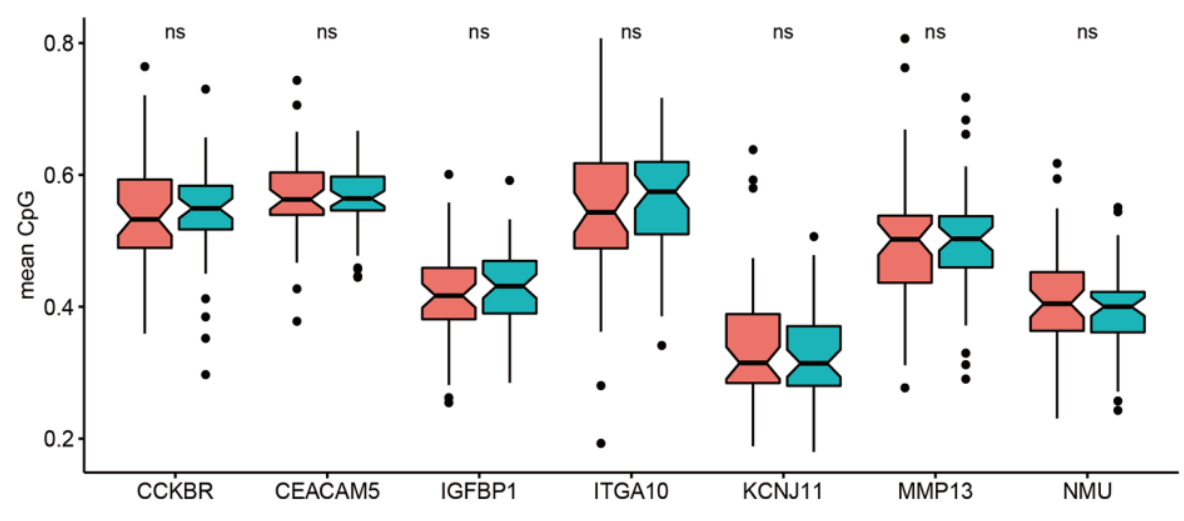

Group 追 Chemotherapy 追 Immunotherapy

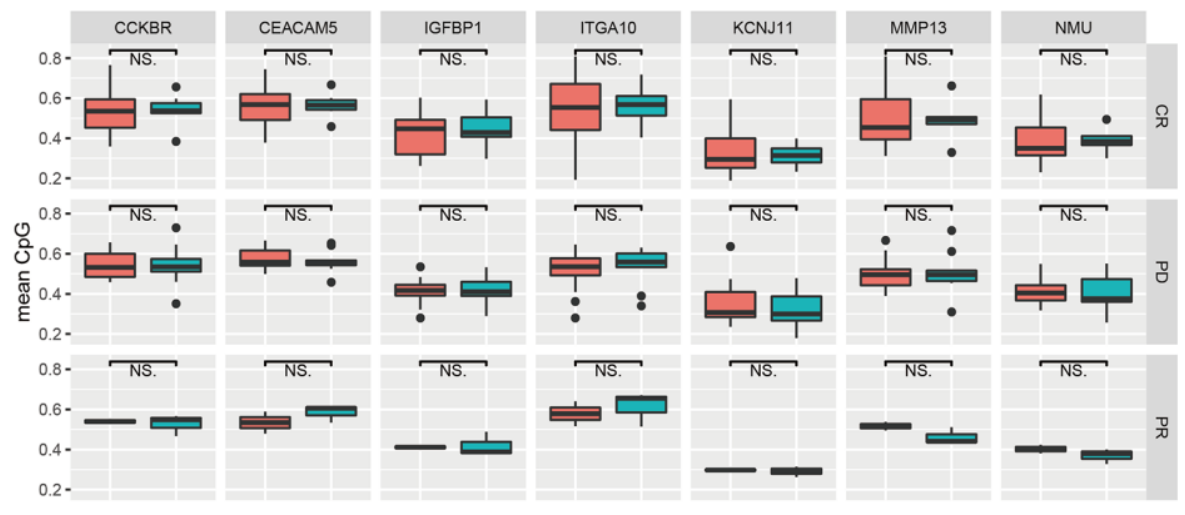

Supplementary Figure 3. Comparison of differences in CpG methylation of signature genes between the two groups. (A) Differences in the distribution of CpG methylation sites of signature genes between groups in chromosomes. (B) The difference in CpG methylation levels between the two groups, as well as in the complete response (CR), partial response (PR) and progressive disease (PD) subgroups. 


\section{Supplementary Tables}

Supplementary Table 1. Primers of signature genes.

\begin{tabular}{cccc}
\hline Symbols & Forward primers $\left(\mathbf{5}^{\prime} \rightarrow \mathbf{3}^{\prime}\right)$ & Reverse primers $\left(\mathbf{5}^{\prime} \rightarrow \mathbf{3}^{\prime}\right)$ & Amplicon size \\
\hline CCKBR & GGGACACGAGAATTGGAGCTG & AACCGCCTTGCAGATGACG & 249 \\
ITGA10 & AACATCACCCACGCCTATTCC & GTTGGTAGTCACCTAAGTGGC & 207 \\
KCNJ11 & AGGTCCAAGTGACTATTGGCT & TCTGCACGATGAGGATCAGGA & 81 \\
IGFBP1 & TTGGGACGCCATCAGTACCTA & TTGGCTAAACTCTCTACGACTCT & 114 \\
NMU & CTCAGGCATCCAACGCACT & GACTTGCCCAACTTCTGTGTC & 136 \\
CEACAM & CTGTCCAATGACAACAGGACC & ACGGTAATAGGTGTATGAGGGG & 174 \\
MMP13 & ACTGAGAGGCTCCGAGAAATG & GAACCCCGCATCTTGGCTT & 103 \\
\hline
\end{tabular}


Supplementary Table 2. 50 important genes screened through PPI network.

\begin{tabular}{|c|c|c|c|c|c|}
\hline Symbols & Gene names & $\begin{array}{c}\log 2 \text { Fold } \\
\text { Change }\end{array}$ & $P$ value & PMID & Function \\
\hline KLK3 & kallikrein related peptidase 3 & 5.400 & $2.52 \mathrm{E}-23$ & 10218588 & angiogenesis \\
\hline SLC17A6 & solute carrier family 17 member 6 & -4.658 & $6.89 \mathrm{E}-20$ & 10820226 & amino acid transmembrane transport \\
\hline CHRNA1 & cholinergic receptor nicotinic alpha 1 subunit & 3.543 & $2.64 \mathrm{E}-12$ & 10195214 & action potential \\
\hline DLK1 & delta like non-canonical Notch ligand 1 & -4.428 & $5.84 \mathrm{E}-12$ & 10354070 & molecular_function \\
\hline SFTPA2 & surfactant protein $\mathrm{A} 2$ & 3.575 & $6.19 \mathrm{E}-12$ & 10781424 & activation of innate immune response \\
\hline FCER1G & Fc fragment of $\mathrm{IgE}$ receptor $\mathrm{Ig}$ & 1.968 & $2.59 \mathrm{E}-10$ & 10049942 & cell activation \\
\hline KRT14 & keratin 14 & -3.028 & $5.63 \mathrm{E}-10$ & 10583131 & molecular_function \\
\hline SFN & stratifin & -2.655 & $3.62 \mathrm{E}-09$ & 10524633 & cell cycle checkpoint \\
\hline ORM1 & orosomucoid 1 & 2.314 & $5.94 \mathrm{E}-09$ & 11027547 & cell activation \\
\hline COL17A1 & collagen type XVII alpha 1 chain & -2.405 & 7.51E-09 & 10022517 & immune system process \\
\hline LMO1 & LIM domain only 1 & -2.211 & $1.28 \mathrm{E}-08$ & 10603358 & $\begin{array}{l}\text { negative regulation of transcription by RNA } \\
\text { polymerase II }\end{array}$ \\
\hline COL6A5 & collagen type VI alpha 5 chain & 2.158 & $1.78 \mathrm{E}-08$ & 14702039 & molecular_function \\
\hline CCKBR & cholecystokinin B receptor & 1.682 & $7.36 \mathrm{E}-08$ & 10100325 & peptide receptor activity \\
\hline ITGA10 & integrin subunit alpha 10 & 2.459 & $1.05 \mathrm{E}-07$ & 10702680 & molecular_function \\
\hline $\mathrm{KCNJ} 11$ & $\begin{array}{l}\text { potassium voltage-gated channel subfamily } \mathrm{J} \\
\text { member } 11\end{array}$ & 1.682 & $1.19 \mathrm{E}-07$ & 10093054 & nucleotide binding \\
\hline EREG & epiregulin & 2.476 & $2.06 \mathrm{E}-07$ & 10681561 & reproduction \\
\hline GABRB2 & $\begin{array}{l}\text { gamma-aminobutyric acid type A receptor beta2 } \\
\text { subunit }\end{array}$ & 1.984 & $2.93 \mathrm{E}-07$ & 10023064 & system process \\
\hline ADCY8 & adenylate cyclase 8 & 2.718 & $3.09 \mathrm{E}-07$ & 10075700 & nucleotide binding \\
\hline KRT16 & keratin 16 & -2.625 & 4.24E-07 & 10521820 & ameboidal-type cell migration \\
\hline NRXN1 & neurexin 1 & -2.371 & 4.33E-07 & 11036064 & cell morphogenesis \\
\hline THBS1 & thrombospondin 1 & 1.612 & 4.47E-07 & 101549 & MAPK cascade \\
\hline IGFBP1 & insulin like growth factor binding protein 1 & 1.507 & 7.07E-07 & 10329650 & regulation of cell growth \\
\hline LIF & LIF interleukin 6 family cytokine & 2.101 & 8.01E-07 & 10205054 & reproduction \\
\hline XAGE2 & $\mathrm{X}$ antigen family member 2 & 2.286 & $2.59 \mathrm{E}-06$ & 10197611 & molecular_function \\
\hline NLGN3 & neuroligin 3 & -1.557 & $3.51 \mathrm{E}-06$ & 10767552 & cell morphogenesis \\
\hline CACNA1B & calcium voltage-gated channel subunit alpha1 B & -2.042 & 4.21E-06 & 10455105 & nucleotide binding \\
\hline KLRD1 & killer cell lectin like receptor D1 & 1.584 & 4.30E-06 & 10023772 & natural killer cell mediated immunity \\
\hline CXCR6 & $\mathrm{C}-\mathrm{X}-\mathrm{C}$ motif chemokine receptor 6 & 1.541 & $5.16 \mathrm{E}-06$ & 10590105 & $\begin{array}{l}\mathrm{G} \text { protein-coupled chemoattractant receptor } \\
\text { activity }\end{array}$ \\
\hline SYT3 & synaptotagmin 3 & -1.794 & $7.08 \mathrm{E}-06$ & 10531343 & cell morphogenesis \\
\hline MCHR1 & melanin concentrating hormone receptor 1 & 2.294 & $1.78 \mathrm{E}-05$ & 10421367 & peptide receptor activity \\
\hline CTSG & cathepsin G & 1.907 & $1.96 \mathrm{E}-05$ & 10512690 & lytic vacuole \\
\hline IVL & involucrin & -2.015 & $2.22 \mathrm{E}-05$ & 10908733 & cornified envelope \\
\hline KRT5 & keratin 5 & -2.084 & $2.25 \mathrm{E}-05$ & 10234505 & molecular_function \\
\hline NMU & neuromedin $\mathrm{U}$ & -1.514 & 2.61E-05 & 10783389 & temperature homeostasis \\
\hline KRT6C & keratin $6 \mathrm{C}$ & -2.036 & $3.51 \mathrm{E}-05$ & 11683385 & molecular_function \\
\hline SAGE1 & sarcoma antigen 1 & 1.560 & $3.65 \mathrm{E}-05$ & 10919659 & cellular_component \\
\hline LRRTM1 & leucine rich repeat transmembrane neuronal 1 & -1.967 & $5.79 \mathrm{E}-05$ & 12477932 & regulation of receptor internalization \\
\hline TCN1 & transcobalamin 1 & 1.801 & $8.91 \mathrm{E}-05$ & 11373332 & transition metal ion transport \\
\hline TEX15 & $\begin{array}{l}\text { testis expressed } 15, \text { meiosis and synapsis } \\
\text { associated }\end{array}$ & -1.854 & 0.000 & 11279525 & reproduction \\
\hline CXCL9 & $\mathrm{C}-\mathrm{X}-\mathrm{C}$ motif chemokine ligand 9 & 1.541 & 0.000 & 10201891 & $\begin{array}{l}\text { syncytium formation by plasma membrane } \\
\text { fusion }\end{array}$ \\
\hline CCL20 & C-C motif chemokine ligand 20 & 1.584 & 0.000 & 10064080 & G protein-coupled receptor binding \\
\hline MMP1 & matrix metallopeptidase 1 & -1.752 & 0.001 & 10224132 & immune system process \\
\hline DDX43 & DEAD-box helicase 43 & -1.587 & 0.001 & 10919659 & nucleotide binding \\
\hline CEACAM5 & $\begin{array}{l}\text { carcinoembryonic antigen related cell adhesion } \\
\text { molecule } 5\end{array}$ & -1.590 & 0.002 & 10436421 & immune system process \\
\hline CXCL5 & $\mathrm{C}-\mathrm{X}-\mathrm{C}$ motif chemokine ligand 5 & 1.666 & 0.002 & 10068592 & molecular_function \\
\hline GRIA2 & $\begin{array}{l}\text { glutamate ionotropic receptor AMPA type } \\
\text { subunit } 2\end{array}$ & 1.586 & 0.003 & 10027300 & amyloid-beta binding \\
\hline VGF & VGF nerve growth factor inducible & 1.554 & 0.004 & 10381005 & reproduction \\
\hline CCL21 & C-C motif chemokine ligand 21 & -1.513 & 0.008 & 10201891 & MAPK cascade \\
\hline MMP13 & matrix metallopeptidase 13 & 1.533 & 0.008 & 10074939 & skeletal system development \\
\hline EDN3 & endothelin 3 & 1.997 & 0.009 & 10231870 & MAPK cascade \\
\hline
\end{tabular}

